\title{
Design Simulation and Fabrication of a Dual Band Frequency Reconfigurable Monopole Antenna for Wi-Fi and WiMAX Applications
}

\author{
Prasanna Paga1, H. C. Nagaraj², T. S. Rukmini² \\ ${ }^{1}$ Department of Electronics, NREA, NMIT, Bangalore, India \\ ${ }^{2}$ Department of ECE, NREA, NMIT, Bangalore, India \\ Email: prasanna.paga@nmit.ac.in,principal@nmit.ac.in,rukminirvce.rao@gmail.com
}

How to cite this paper: Paga, P., Nagaraj, H.C. and Rukmini, T.S. (2017) Design Simulation and Fabrication of a Dual Band Frequency Reconfigurable Monopole Antenna for Wi-Fi and WiMAX Applications. Open Journal of Antennas and Propagation, 5, 151-167.

https://doi.org/10.4236/ojapr.2017.53012

Received: May 23, 2017

Accepted: September 25, 2017

Published: September 28, 2017

Copyright $\odot 2017$ by authors and Scientific Research Publishing Inc. This work is licensed under the Creative Commons Attribution International License (CC BY 4.0).

http://creativecommons.org/licenses/by/4.0/

\begin{abstract}
Nowadays, wireless systems require compact multi band antennas that can dynamically change some of its fundamental parameters such as frequency band, polarization and radiation pattern. The novelty of the proposed work lies in using two conducting strips that are perpendicular to each other. The longer strip resonates at $2.4 \mathrm{GHz}$ and the shorter strip resonates at $3.5 \mathrm{GHz}$. The length and width of the Ground plane is made equal to length of the main arm and length of the side arm respectively. The results are obtained by simulating the antenna structure using simulation tool Ansoft HFSS v15.0. The Simulated antenna Gains were $6.2364 \mathrm{dBi}$ and $7.1758 \mathrm{dBi}$ for frequencies of $2.4 \mathrm{GHz}$ and $3.5 \mathrm{GHz}$ respectively. The antenna dimensions are $50 \times 25 \times 1.6$ $\mathrm{mm}^{3}$ on a $1.6 \mathrm{~mm}$ thick FR-4 substrate.
\end{abstract}

\section{Keywords}

Monopole, Frequency Reconfigurability, WiFi, WiMAX, FR4

\section{Introduction}

Monopole antennas have become the most preferred choice in the domain of the Wi-Fi and WiMAX applications and other fields like Bluetooth cards and wireless communications. In the present work, Monopole classes of Antennas are selected which are compact in size and normally the gains are low. To excite dual bands, two conductors of different lengths are chosen that are perpendicular to each other. The length of the longer strip is designed for resonating at $2.4 \mathrm{GHz}$ while the shorter strip is designed for $3.5 \mathrm{GHz}$. The novelty of the proposed work lies in making the length of the Ground plane equal to the length of the 
main arm and the width of ground plane correspond to the side arm width of the. The main contribution of the research work is in getting a huge bandwidth of $2.16 \mathrm{GHz}$ corresponding to $3.5 \mathrm{GHz}$, very high peak gains of $6.236 \mathrm{dBi}$ and $7.17 \mathrm{dBi}$ for Wi-Fi and WiMAX bands respectively. The measured radiation pattern is nearly omni-directional in both the $\mathrm{E}$ and the $\mathrm{H}$ planes for both 2.4 $\mathrm{GHz}$ and $3.5 \mathrm{GHz}$ frequency bands.

In [1], a printed monopole antenna with a low profile on a FR4 substrate is proposed. The Antenna structure resembles a figure of $\mathrm{T}$. The proposed Antenna results in a resonant frequency of $2.4 \mathrm{GHz}$ and is very compact in size. In [2], a dual band printed Monopole Antenna resonating at two frequencies namely $900 \mathrm{MHz}$ (GSM band) and $2.4 \mathrm{GHz}$ (Wi-Fi band) has been proposed on a FR4 substrate. The proposed antenna resulted in a return loss of $-33 \mathrm{~dB}$ and $-35 \mathrm{~dB}$ for both the lower and the upper frequency bands respectively. The VSWR obtained is between 1 and 2 for both the bands. The Bandwidth of the proposed antenna was $104 \mathrm{MHz}$ and $350 \mathrm{MHz}$ for $900 \mathrm{MHz}$ and $2.4 \mathrm{GHz}$ band respectively. In [3], a novel 9-shaped multiband frequency reconfigurable monopole antenna for wireless applications, using $1.6 \mathrm{~mm}$ thick FR4 substrate and a truncated metallic ground surface, has been proposed. The designed antenna operates in single and dual frequency mode based on switching states. The antenna operates in WiMAX band resonating at $3.5 \mathrm{GHz}$ when the switch is in the OFF state. The structure operates in $2.45 \mathrm{GHz}$ and $5.2 \mathrm{GHz}$ when the switch is turned ON. The antenna resulted in a Gain of $1.48 \mathrm{dBi}, 2.47 \mathrm{dBi}$ and $3.26 \mathrm{dBi}$ for frequencies of $2.45 \mathrm{GHz}, 3.5 \mathrm{GHz}$ and $5.2 \mathrm{GHz}$ respectively. The proposed antenna is compact in size with a dimension of $40 \times 35 \times 1.6 \mathrm{~mm}^{3}$, light weight, and highly efficient (84\% - 92\%). It can be used in Wi-Fi, WiMAX and WLAN based wireless applications. In [4], a tri-band monopole antenna has been proposed to resonate at $2.4 \mathrm{GHz}, 3.5 \mathrm{GHz}$ and $5.5 \mathrm{GHz}$ Applications. The bandwidths reported were $340 \mathrm{MHz}(2.4-2.74 \mathrm{GHz}), 340 \mathrm{MHz}(3.41-3.75 \mathrm{GHz})$, and 640 $\mathrm{MHz}(5.24-5.88 \mathrm{GHz})$, respectively, for $2.4 \mathrm{GHz}, 3.5 \mathrm{GHz}$ and $5.5 \mathrm{GHz}$ indicating this antenna is suitable for WLAN and WiMAX applications. The antenna resulted in a return loss value less than $-10 \mathrm{~dB}$ for all the three frequencies. Gain of proposed antenna was $2.08 \mathrm{dBi}, 1.93 \mathrm{dBi}$ and $2.48 \mathrm{dBi}$ for $2.5 \mathrm{GHz}, 3.5 \mathrm{GHz}$ and $5.5 \mathrm{GHz}$ respectively. The proposed antenna is compact in size and has nearly omni-directional radiation characteristics and constant gains over all the operating frequency bands. In [5], a compact antenna with a modified Ground structure is presented. The antenna gives a bandwidth of $400 \mathrm{MHz}$ and $530 \mathrm{MHz}$ for $2.5 \mathrm{GHz}$ and $3.5 \mathrm{GHz}$ respectively. It also gives a omni-directional pattern with a peak gain of $1.9 \mathrm{dBi}$ and $2.7 \mathrm{dBi}$ for the lower and upper frequency bands respectively. In [6], a compact triple-band printed monopole antenna for WLAN and WiMAX applications has been proposed. The Bandwidth reported in the Antenna was $100 \mathrm{MHz}$ for $2.4 \mathrm{GHz}, 500 \mathrm{MHz}$ for $3.5 \mathrm{GHz}$ and $610 \mathrm{MHz}$ for 5.5 $\mathrm{GHz}$. The radiation pattern of the Antenna is omni-directional in nature. The Antenna resulted in a Gain of $1.55 \mathrm{dBi}, 1.6 \mathrm{dBi}$ and $2.05 \mathrm{dBi}$ for $2.45 \mathrm{GHz}, 3.5$ $\mathrm{GHz}$ and $5.6 \mathrm{GHz}$ respectively. In [7], a Tri band Antenna with a modified 
Ground plane has been proposed for WLAN and WiMAX applications. By inserting inverted $\mathrm{L}$ shaped strips and perturbations in the Ground plane resulted in a resonant frequency of $2.4 \mathrm{GHz}, 3.5 \mathrm{GHz}$ and $5.2 \mathrm{GHz}$. The structure size reported were $20 \mathrm{~mm} \times 27 \mathrm{~mm} \times 1 \mathrm{~mm}$. The Bandwidth of the proposed antenna was $180 \mathrm{MHz}, 380 \mathrm{MHz}$ and $280 \mathrm{MHz}$ covering both the 2.4, 5.2 GHz WLAN and $3.5 \mathrm{GHz}$ WiMAX bands. The Antenna Gains reported were between 2.06 to $2.78 \mathrm{dBi}$ for the lower band, $2.14 \mathrm{dBi}$ for the $3.5 \mathrm{GHz}$ and the $5.2 \mathrm{GHz}$ bands respectively. In [8], a pentagonal shaped monopole Antenna with defected Ground structure is presented. The Antenna is etched on a FR4 substrate and compact in shape. The Antenna resonates at $1.8 \mathrm{GHz}$ and $3.5 \mathrm{GHz}$. The antenna gives a gain of $0.611 \mathrm{~dB}$ and $3.56 \mathrm{~dB}$ for frequencies of $1.847 \mathrm{GHz}$ and $3.474 \mathrm{GHz}$ respectively. The Bandwidth of the proposed antenna was $90 \mathrm{MHz}$ and $150 \mathrm{MHz}$ respectively for DCS and WiMAX bands respectively. In [9], dual-band monopole antenna is presented for resonating at $900 \mathrm{MHz}$ and $1.8 \mathrm{GHz}$ covering the GSM 900 and GSM 1800 bands respectively. The proposed design can be used as an Energy Harvesting system. The Antenna was printed on a FR4 substrate. The return loss values were $-30 \mathrm{~dB}$ and $-25.5 \mathrm{~dB}$ for GSM 900 and 1800 bands respectively. The Gains reported were $-1.64 \mathrm{~dB}$ and $0.85 \mathrm{~dB}$ for the lower and the upper bands respectively. Bandwidths of the proposed Antenna were $124 \mathrm{MHz}$ and $196 \mathrm{MHz}$ covering lower and upper GSM bands respectively.

In [10], a compact slotted multi-band monopole antenna has been proposed for WLAN and WiMAX applications. The proposed antenna has a size of $30 \mathrm{~mm}$ $\times 25 \mathrm{~mm} \times 1 \mathrm{~mm}$. The designed antenna obtained three frequency bands namely 2.4 GHz, 3.5 GHz and 5.8 GHz covering the WLAN and the Wi-Max bands. The current path is changed by using inverted $\mathrm{E}$ and $\mathrm{C}$ shaped slot. The structure resulted in a Bandwidth of $51 \mathrm{MHz}, 450 \mathrm{MHz}$ for the WLAN $2.4 \mathrm{GHz}$ and $5.5 \mathrm{GHz}$ and $251 \mathrm{MHz}$ for the Wi-Max band. In [11], a simple multiband metamaterial-loaded monopole antenna suitable for WLAN and Wi-Max has been proposed. The rectangular Monopole antenna was originally designed to resonate at $5.2 \mathrm{GHz}$. When the inverted-L slot is etched, the antenna produces a second resonance at around $4.1 \mathrm{GHz}$. Then, with the addition of the metamaterial reactive loading, a third resonance covering the $2.4-\mathrm{GHz}$ band occurs. Consequently, the antenna can cover the 2.4/5.2/5.8 GHz WLAN and 2.5/3.5/5.5 GHz WiMAX bands with a very compact size. In [12], design of a dual-band monopole antenna with microstrip fed for use in wireless devices in the WiMAX system is presented. The antenna radiator has a compact size of only $14.5 \times 8.7 \mathrm{~mm}^{2}$ and consists of a short stem and two branches resonating at around $2.4 \mathrm{GHz}$ and 3.5 $\mathrm{GHz}$ for the WLAN and WiMAX bands. In [13], a circularly polarized planar monopole antenna is presented. By inserting the $\mathrm{L}$ and the $\mathrm{C}$ shaped strips on the patch, two frequency bands were obtained. The structure has a compact size of $40 \times 47 \times 1.5 \mathrm{~mm}^{3}$. The Bandwidths of the proposed Antenna were $380 \mathrm{MHz}$ and $1240 \mathrm{MHz}$ for the $2.4 \mathrm{GHz}$ and the $5.2 \mathrm{GHz}$ bands respectively. The patterns have the characteristic of bidirectional radiation, and the gains are stable in both bands. In [14], multi band Monopole Antennas, covering three frequencies using 
Defective Ground plane structures were realized. The novelty of the proposed work lies in dual inverted L-shaped strips and is fed by a cross-shaped stripline. This technique resulted in creating additional bands and improved Bandwidth. The size of the Antenna reported were $20 \mathrm{~mm} \times 30 \mathrm{~mm}^{2}$, covering the WLAN and Wi-Max Applications. In [15], a multiband bow-tie monopole antenna with Co-planar waveguide feed is proposed. To cover different frequency bands, slots of different lengths were etched in the bow-tie patch. The Antenna resulted in a peak Gain of $3.75 \mathrm{dBi}, 3.56 \mathrm{dBi}$ and $3.93 \mathrm{dBi}$ covering the $2.5 \mathrm{GHz}, 3.5 \mathrm{GHz}$ and $5.5 \mathrm{GHz}$ bands respectively.

\section{Design Methodology}

In our proposed work, the main antenna is designed to resonate at $2.4 \mathrm{GHz}$

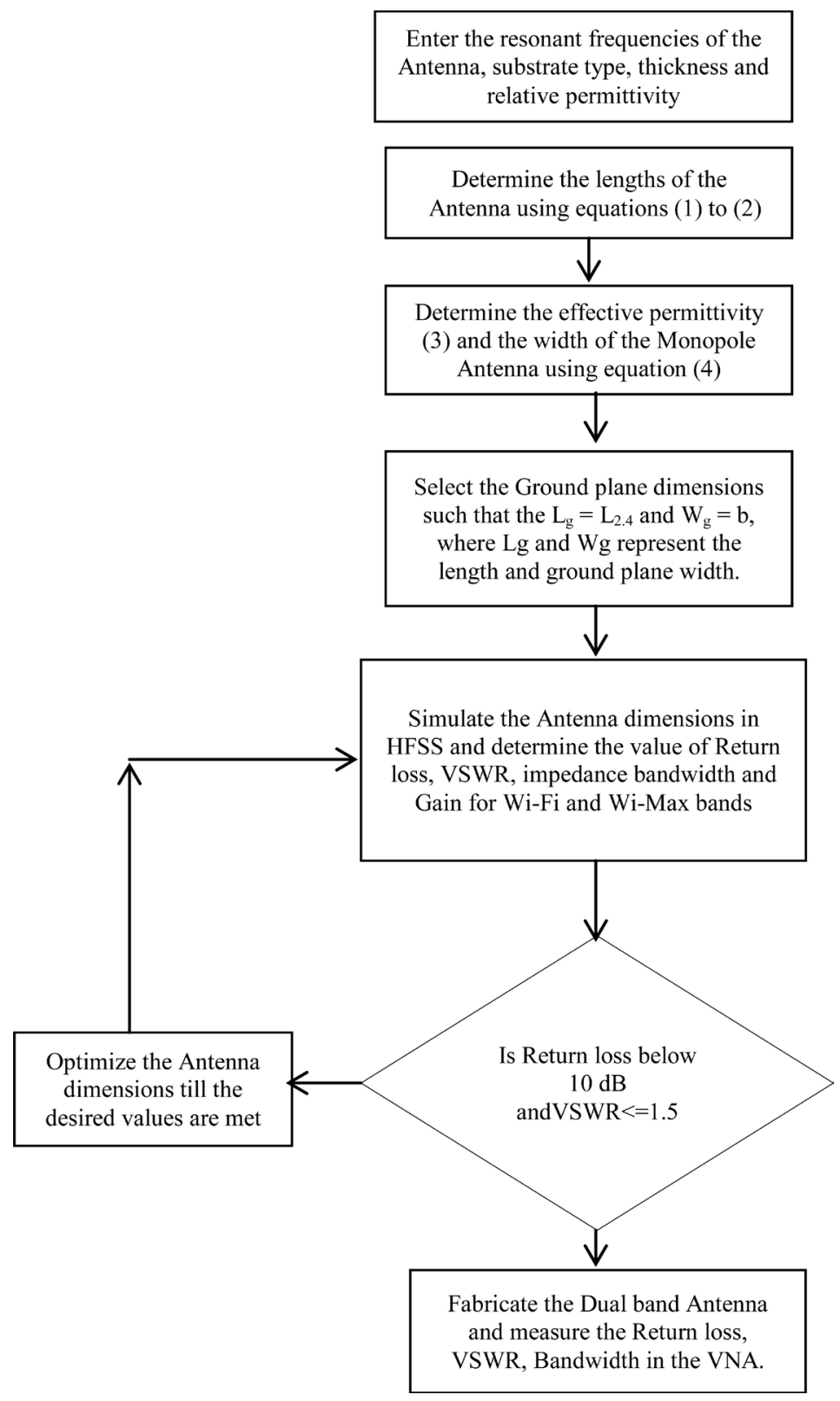


which is shown by the longer monopole of length $\mathrm{L}_{2.4}$ and side arm is inserted towards the right of the longer monopole antenna so as to create an additional resonant frequency of $3.5 \mathrm{GHz}$. The substrate chosen here is a FR4 type which has a dielectric loss tangent of 0.02 and permittivity of 4.4. The substrate thickness is kept equal to $1.6 \mathrm{~mm}$. The length and width of the ground planes are selected such that the antenna size becomes compact, with the length of the ground plane kept equal to $\mathrm{L}_{2.4}$ and width of the ground plane is selected such that it is approximately equal to the length of the side arm of the monopole.

\section{Antenna Design}

In the proposed design, the Ground plane has been partially removed to give it a Monopole like structure.

\section{Design Equations}

Figure 1 shows the snap shot of the antenna designed in HFSS clearly indicating the substrate, the Antenna and the Ground plane. Figure 2 shows the fabricated

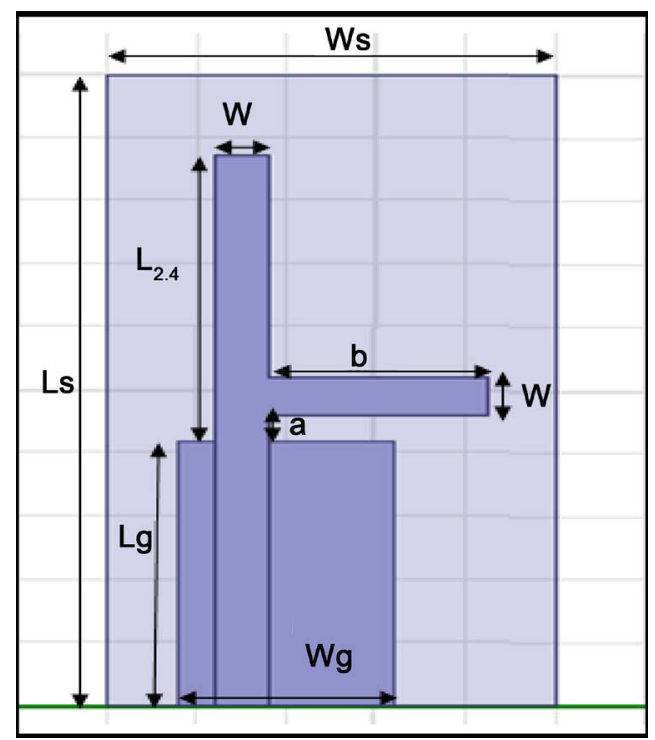

Keynote 1: $\mathrm{L}_{2.4}$ represents the length of the monopole resonating at $2.4 \mathrm{GHz}$ and $\mathrm{b}$ represents the section contributing for resonance at $3.5 \mathrm{GHz}$.

Figure 1. Snapshot of the proposed Dual frequency Monopole Antenna in HFSS.

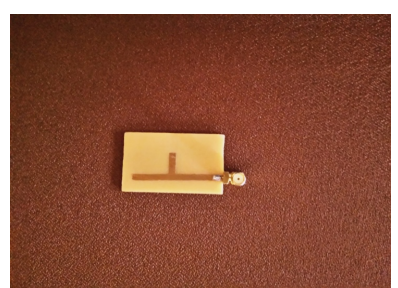

(a)

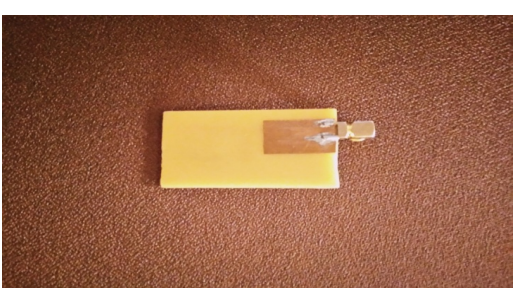

(b)

Keynote 2: Antenna dimensions are $50 \mathrm{~mm}$ by $25 \mathrm{~mm}$ on FR4 substrate of thickness $1.6 \mathrm{~mm}$.

Figure 2. (a) Fabricated Dual band Antenna (b) Ground plane view. 
prototype of the Antenna. The selection of the length and width of the Monopole has been done using the following equations [1] \& [16]

$$
\begin{gathered}
L_{2.4 G H z}=\frac{\lambda g}{4} \\
\lambda g=\frac{\lambda_{0}}{\sqrt{\varepsilon_{\text {reff }}}} \\
\varepsilon_{\text {reff }}=\left[\left(\frac{\varepsilon_{r}+1}{2}\right)+\left(\frac{\varepsilon_{r}-1}{2}\right)\left(1+\frac{12 h}{W}\right)^{\frac{-1}{2}}\right] \\
Z=\frac{60}{\sqrt{\varepsilon_{\text {reff }}}} \ln \left[\frac{8 h}{W}+\frac{W}{4 h}\right] \\
L_{3.5 \mathrm{GHz}}=a+b=\frac{\lambda g}{4} \\
L s=6 h+L \\
W s=6 h+W
\end{gathered}
$$

where $\mathrm{L}_{1}=$ Length of the Main Monopole resonating at $2.4 \mathrm{GHz}$.

$\lambda g=$ Guide wavelength.

$\varepsilon_{\text {reff }}=$ Effective electrical permittivity of the dielectric substrate.

$\lambda_{0}=$ Free space wavelength corresponding to frequency of operation.

$\varepsilon_{r}=$ Relative dielectric constant of the substrate.

$W=$ Monopole Antenna width.

$H=$ Substrate thickness $=1.6 \mathrm{~mm}$.

$Z=50 \mathrm{Ohms}$ (port Impedance).

$W=$ Width of the Monopole.

$a=$ Gap width.

$b=$ Side Lengths of the Monopole.

$L s=$ Substrate Length.

$W s=$ Substrate Width.

\section{Proposed Algorithm}

(i) Select the Antenna dimensions require using Equations (1) to (3)

(ii) Select the substrate type required, thickness and relative permittivity

(iii) Determine the value of effective permittivity using (3)

(iv) Simulate the Antenna for $2.4 \mathrm{GHz}$ with the theoretical length.

(v) Determine the values of Return loss, VSWR, Impedance bandwidth and Gain.

(vi) Is the Return loss well below $-10 \mathrm{~dB}$ and VSWR $<1.5$.

(vii) Optimize the antenna dimensions and repeat the steps (v) and (vi).

(viii) Insert a side arm perpendicular to the main arm using the theoretical length calculated for $3.5 \mathrm{GHz}$.

(ix) Repeat steps (v) to (vii) until all the parameters are as desired. 
(x) Antenna is fabricated on a FR4 substrate. Simulated and measured results are compared.

\section{Simulation \& Measured Results}

The Antenna has been simulated under HFSS version 15.0 and also fabricated and tested with VNA. The results are indicated as shown.

\section{Results and Discussions}

The Dual band Antenna resonating at Wi-Fi and Wi-Maxband which is reported here is fabricated and experimentally tested with dimensions as reported in Table 1 . The substrate lengths and widths were set equal to $50 \mathrm{~mm}$ by $25 \mathrm{~mm}$. The Length and width of the ground plane was theoretically set equal to quarter of the Guide wavelength corresponding to $2.4 \mathrm{GHz}$ and $3.5 \mathrm{GHz}$ respectively. The Length of the longer monopole arm was set equal to a quarter of the Guide wavelength corresponding to $2.4 \mathrm{GHz}$ frequency and the side arm length which is perpendicular to main arm is set equal to quarter of the Guide wavelength corresponding to $3.5 \mathrm{GHz}$ frequency. After theoretical calculations it was found to be $17.1 \mathrm{~mm}$. The length of the side $\operatorname{arm}(\mathrm{a}+\mathrm{b})$ was calculated at Quarter wavelength resonance condition to arrive at $11.7 \mathrm{~mm}$. Further optimization was done on the longer arm and the side arm resulting in a length of $22.6 \mathrm{~mm}$ and 14.3 $\mathrm{mm}$ respectively. The width of the feed was calculated using Equation (4) taking the port impedance as $50 \mathrm{Ohms}$ substrate height as $1.6 \mathrm{~mm}$ and effective permittivity as 4 , to arrive at the feed width of $3.0 \mathrm{~mm}$. Figure 3 and Figure 4 show the simulated and measured return loss of the proposed Antennas. The Return loss of the fabricated Dual band Antenna was measured using VNA MASTER MS2308C. Two resonant modes were excited $2.4 \mathrm{GHz}$ and $3.5 \mathrm{GHz}$. The measured values were $2.7 \mathrm{GHz}$ and $3.426 \mathrm{GHz}$ with an impedance Bandwidth of 0.26 $\mathrm{GHz}$ and $2.16 \mathrm{GHz}$. The bandwidth reported in the upper band was the highest. The measured value of VSWR reported in the Wi-Fi band was 1.53 and that in the Wi-Max band was 1.09 indicating a good impedance match at the upper. The measured values as seen from Figure 4 were $2.7 \mathrm{GHz}$ and $3.426 \mathrm{GHz}$ with an impedance Bandwidth of $0.26 \mathrm{GHz}$ and $2.16 \mathrm{GHz}$ as reported in Figure 9. The VSWR reported in Figure 5 is close to 1 indicating a good impedance match. The bandwidth reported in the upper band was the highest. From the Figure 6, the measured value of VSWR reported in the Wi-Fi band was 1.53 and that in the Wi-Max band was 1.09 indicating a good impedance match at the upper band compared to the lower band. Comparing Figure 7 and Figure 8, the simulated Bandwidth reported is $330 \mathrm{MHz}$ and $412 \mathrm{MHz}$ for Wi-Fi and the Wi-Max Frequency bands respectively. From Figure 10, peak value Gain is $6.23 \mathrm{~dB}$ for $2.4 \mathrm{GHz}$, and $7.17 \mathrm{dBi}$ in the $3.5 \mathrm{GHz}$ band. The measured radiation pattern as reported in Figure 13 and Figure 14, show that the pattern is omnidirectional for both the $2.4 \mathrm{GHz}$ and the $3.5 \mathrm{GHz}$ frequency bands respectively. Referring to Table 2, we see that the return loss value is more negative in the $2.4 \mathrm{GHz}$ band 
Table 1. Geometrical specifications of the Antenna.

\begin{tabular}{ccc}
\hline Antenna specifications & Theoretical Value & Optimized Value \\
\hline Substrate Length $(\mathrm{Ls})$ & $50 \mathrm{~mm}$ & $50 \mathrm{~mm}$ \\
Substrate Width $(\mathrm{Ws})$ & $25 \mathrm{~mm}$ & $25 \mathrm{~mm}$ \\
Ground plane Length $(\mathrm{Lg})$ & $26.7 \mathrm{~mm}$ & $21 \mathrm{~mm}$ \\
Ground plane width $(\mathrm{Wg})$ & $12.6 \mathrm{~mm}$ & $12.0 \mathrm{~mm}$ \\
Feed width $(\mathrm{w})$ & $3.0 \mathrm{~mm}$ & $3.0 \mathrm{~mm}$ \\
Length of longer arm $\left(\mathrm{L}_{2.4}\right)$ & $17.1 \mathrm{~mm}$ & $22.6 \mathrm{~mm}$ \\
Length of the side arm $(\mathrm{a}+\mathrm{b})$ & $11.7 \mathrm{~mm}$ & $14.3 \mathrm{~mm}$ \\
\hline
\end{tabular}

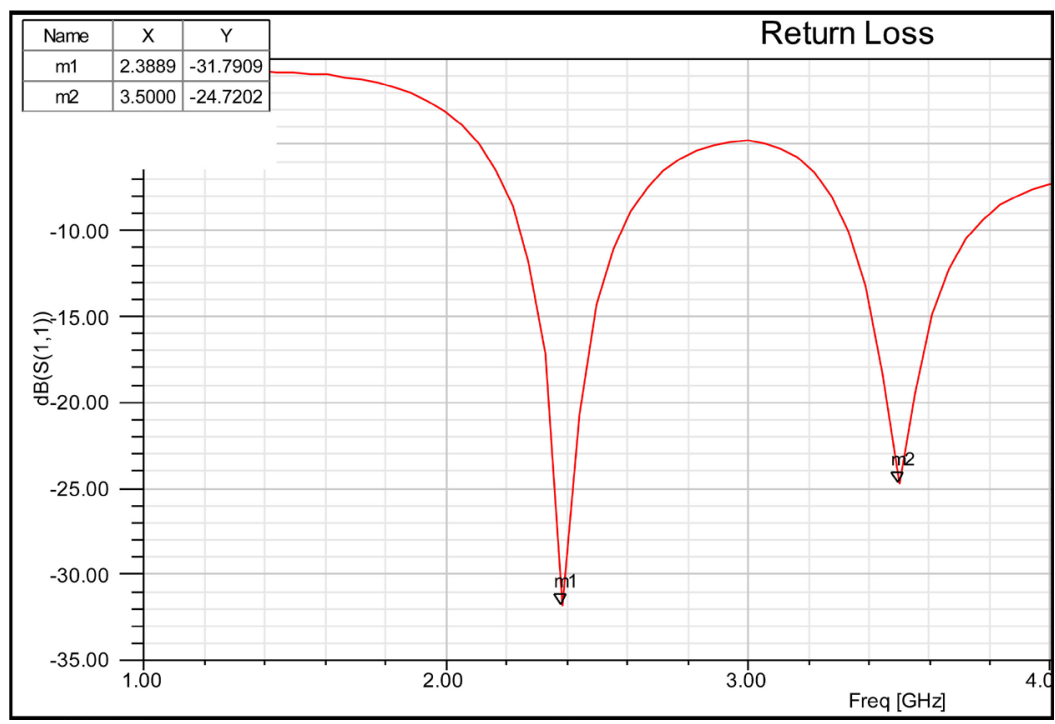

Keynote 3: markers $\mathrm{m} 1$ and $\mathrm{m} 2$ indicate a return loss of $-31.79 \mathrm{~dB} \&-24.72 \mathrm{~dB}$ for $2.4 \mathrm{GHz}$ and $3.5 \mathrm{GHz}$.

Figure 3. Return Loss plot of the Monopole Antenna resonating at 2.4 and $3.5 \mathrm{GHz}$.

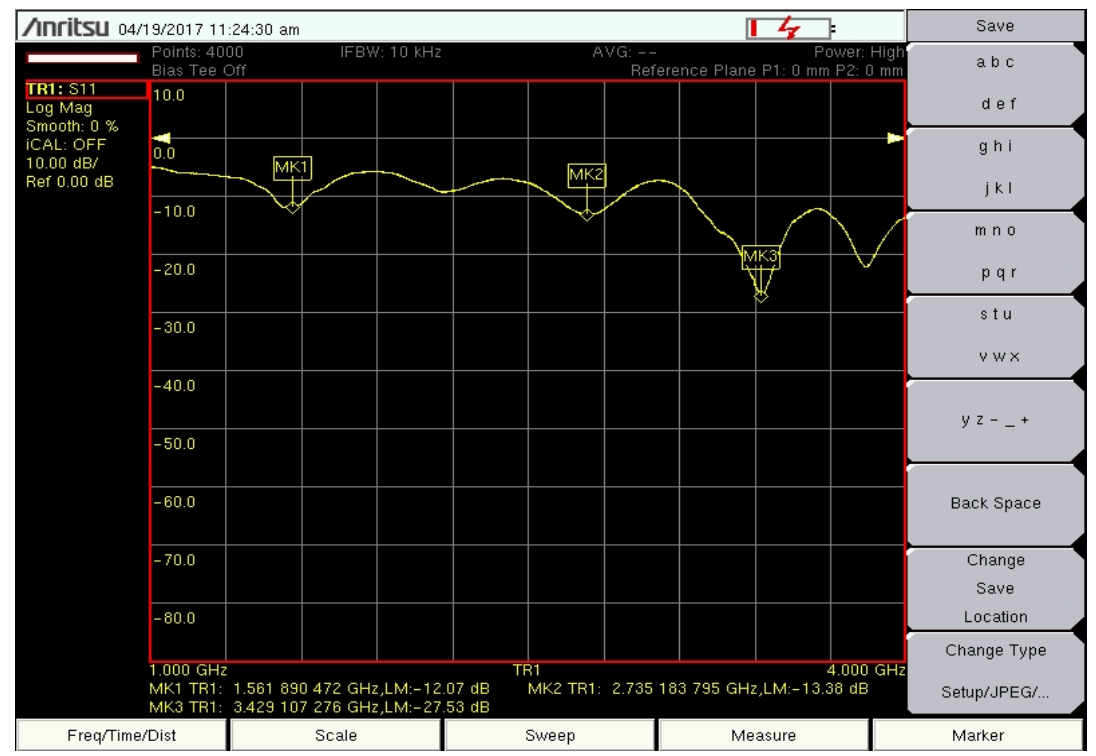

Keynote 4: The Horizontal Axis represents the Frequency in GHz and the vertical Axis represents the Return Loss in $\mathrm{dB}$ markers MK2 and MK3 represent $2.7 \mathrm{GHz}$ and $3.5 \mathrm{GHz}$.

Figure 4. Measured Return Loss plot of the Fabricated Monopole Antenna. The Return loss value is $-13.38 \mathrm{~dB}$ at $2.72 \mathrm{GHz}$ as indicated by marker MK2 and $-27.53 \mathrm{~dB}$ at 3.5 $\mathrm{GHz}$ corresponding to marker MK3. 


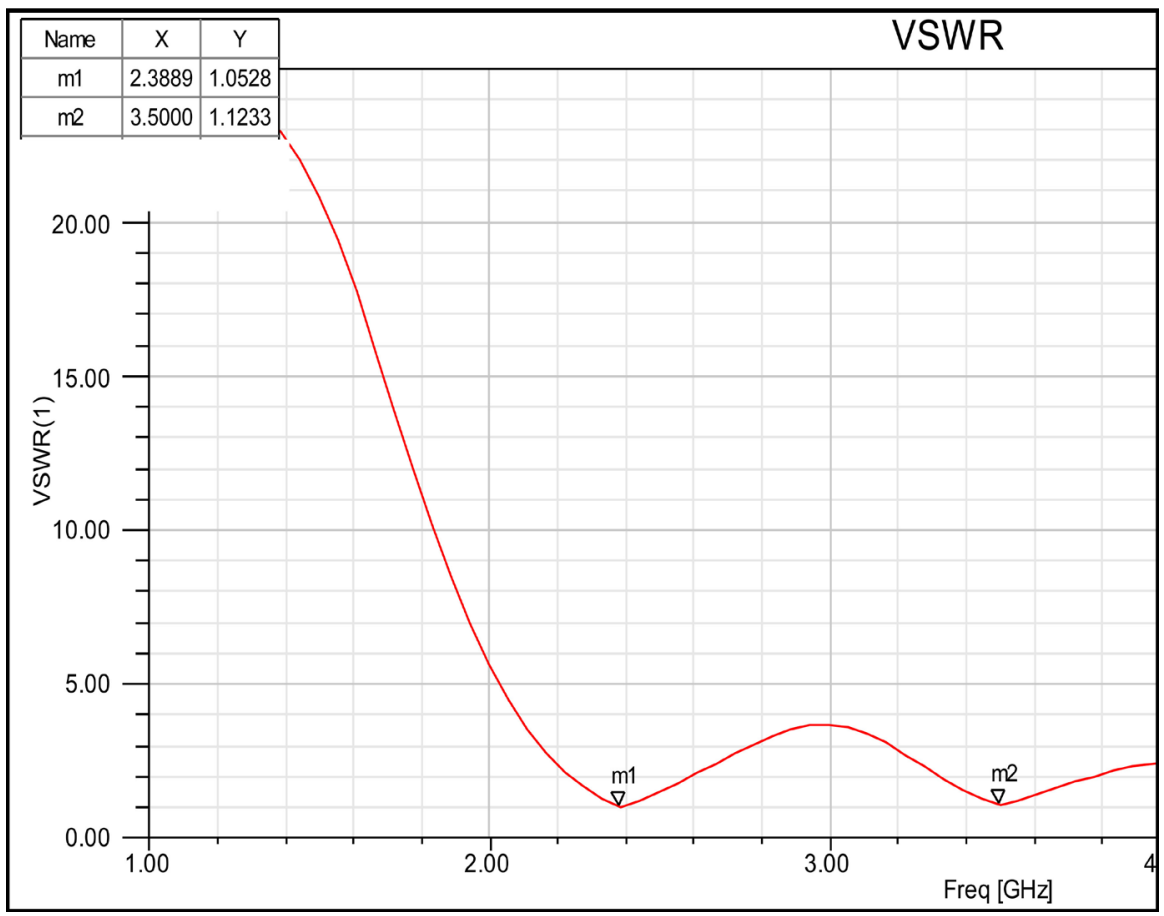

Keynote 5: Markers $\mathrm{m} 1$ and $\mathrm{m} 2$ indicate a VSWR value of 1.05 and 1.12 for $2.4 \mathrm{GHz}$ and $3.5 \mathrm{GHz}$.

Figure 5. Simulated VSWR plot of the Monopole Antenna resonating at $2.4 \mathrm{GHz}$ and 3.5 GHz. The corresponding values of VSWR are 1.05 and 1.12 as indicated by markers $\mathrm{m} 1$ and $\mathrm{m} 2$.

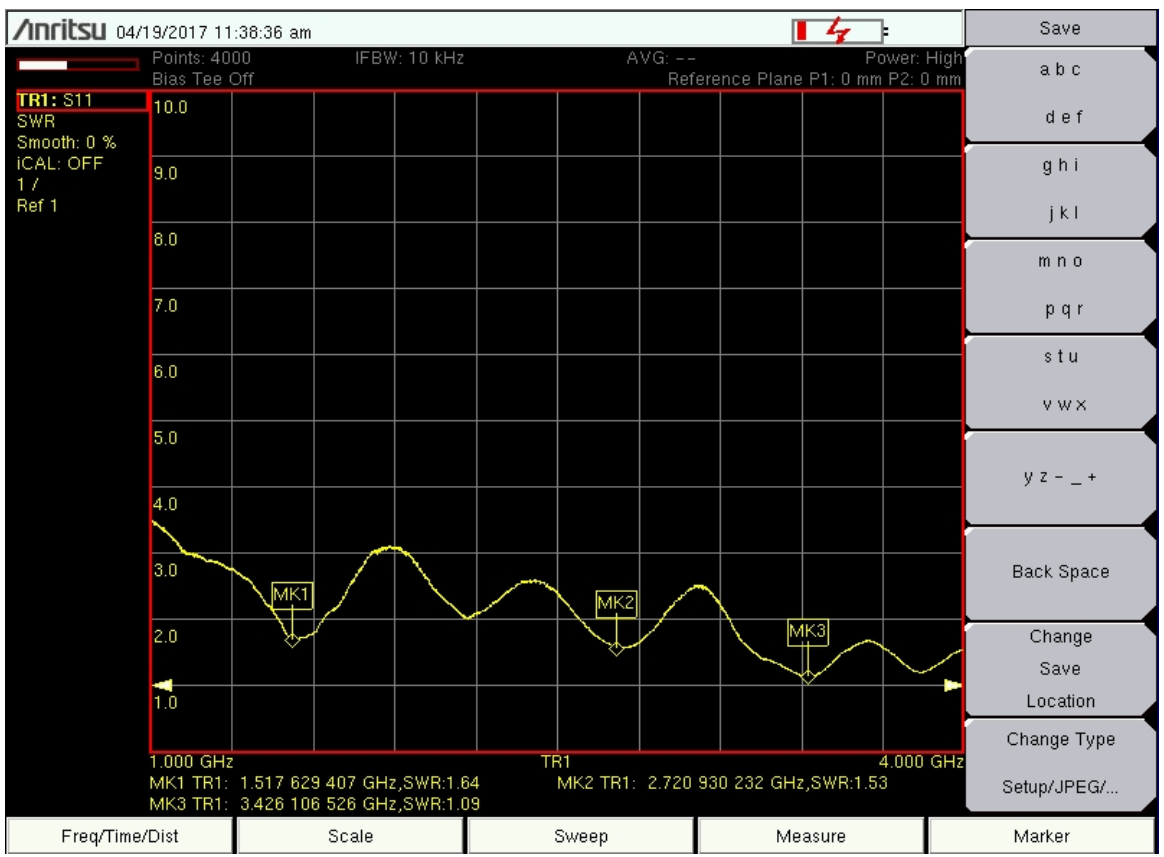

Keynote 6: The Horizontal axis represents the Frequency in GHz and the vertical Axis represents the VSWR. The markers MK2 and MK3 represent the VSWR corresponding to 1.53 and 1.09 for 2.7 $\mathrm{GHz}$ and $3.5 \mathrm{GHz}$.

Figure 6. Measured VSWR plot of the Monopole Antenna resonating at $2.4 \mathrm{GHz}$ and 3.5 $\mathrm{GHz}$ as shown by markers MK2 and MK3. The corresponding values are 1.53 and 1.09 for lower and upper band respectively. 


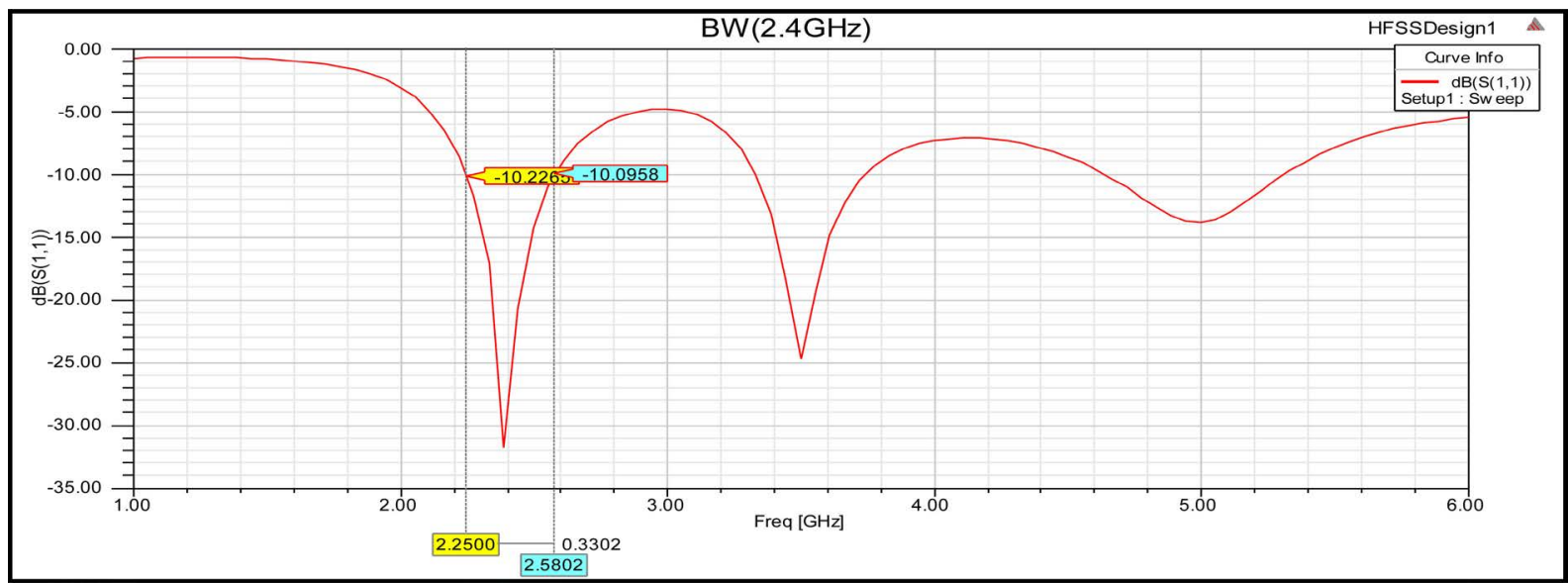

Figure 7. Simulated Bandwidth of the Monopole Antenna resonating at $2.4 \mathrm{GHz}$ indicating a Bandwidth of $330.2 \mathrm{MHz}$.

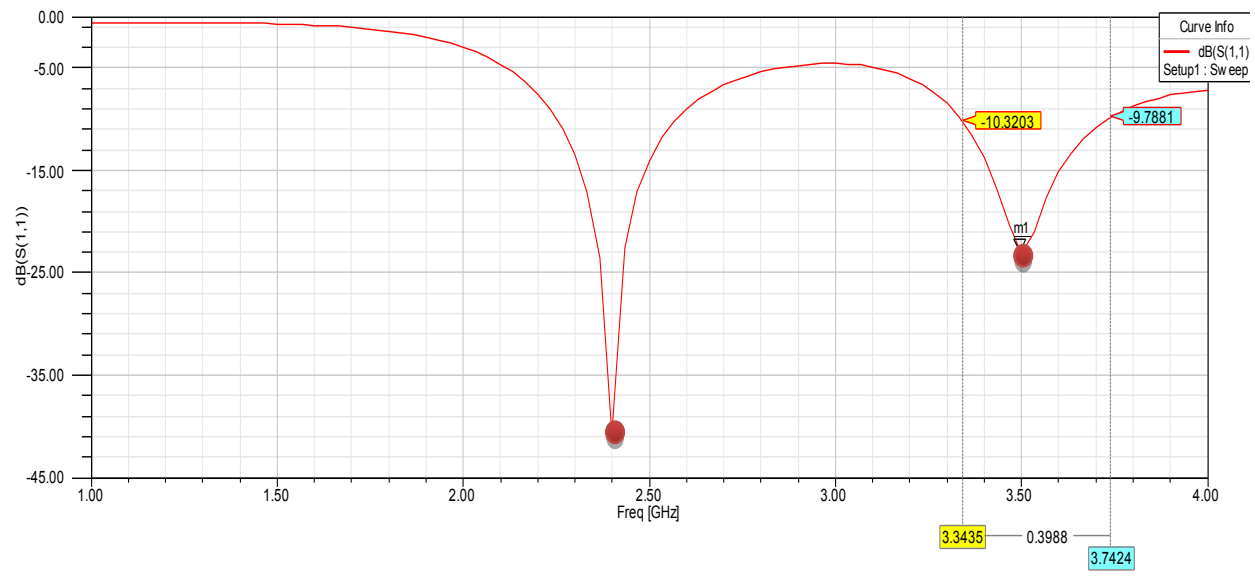

Keynote 8: Horizontal Axis represents the Frequency in GHz and the Vertical axis represents the return loss in $\mathrm{dB}$.

Figure 8. Simulated Bandwidth of the Monopole Antenna resonating at $3.5 \mathrm{GHz}$ indicating a Bandwidth of $412.7 \mathrm{MHz}$. From the figure, the lower $-10 \mathrm{~dB}$ frequency is $3.33 \mathrm{GHz}$ and the upper $-10 \mathrm{~dB}$ frequency is $3.747 \mathrm{GHz}$ and the difference gives the Bandwidth.

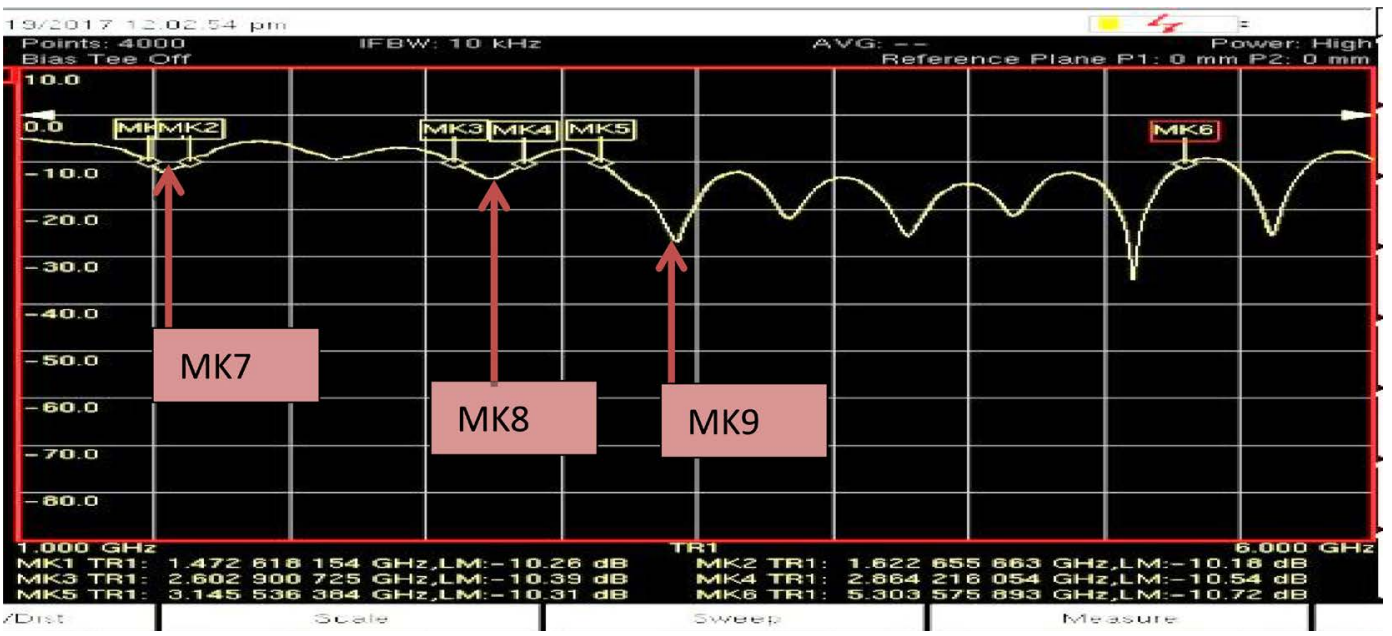

Keynote 9: Horizontal Axis represents the Frequency in GHz and the Vertical Axis represents the Return loss in dB.

Figure 9. Measured Bandwidth of the Dual band Antenna resonating at 2.4 GHz 3.5 GHz as shown by markers MK3, MK4, MK5 and MK6 indicating a Bandwidth of $262 \mathrm{MHz}$ and $2.158 \mathrm{GHz}$ for Wi-Fi and Wi-Max. The markers MK7, MK8 and MK9 indicate the resonant frequencies of $1.5 \mathrm{GHz}, 2.7 \mathrm{GHz}$ and $3.429 \mathrm{GHz}$. 


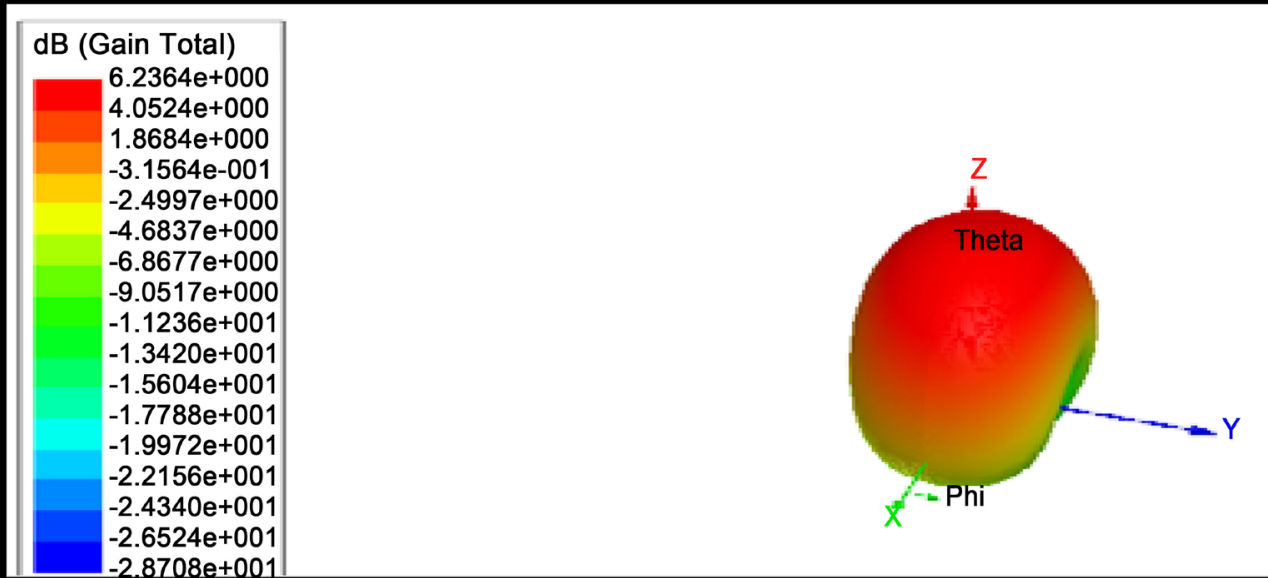

(a)
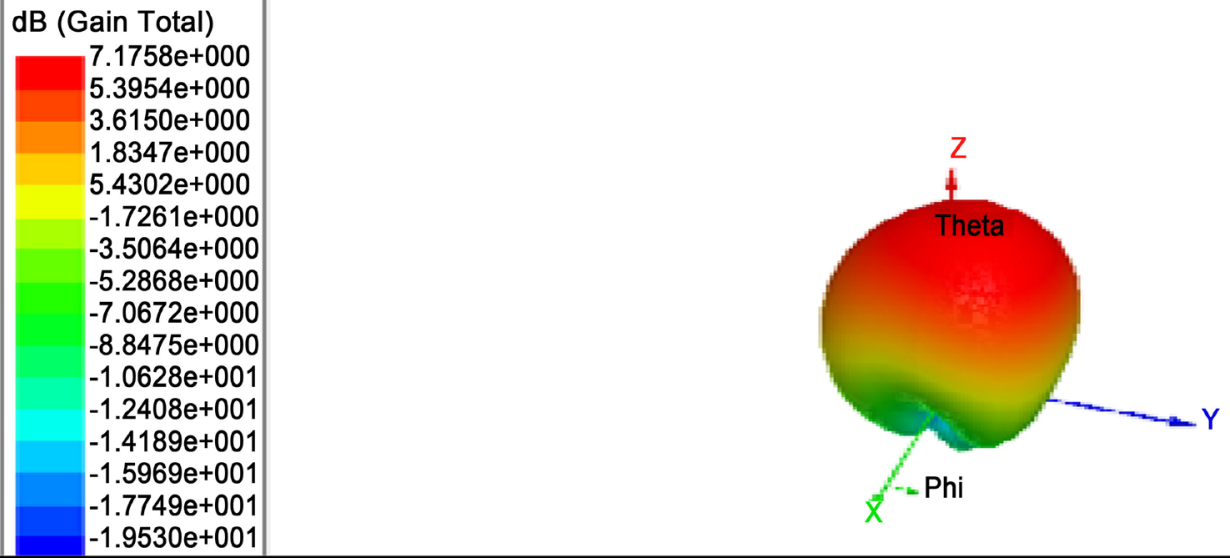

(b)

Figure 10. (a) Simulated Gain plot for $2.4 \mathrm{GHz}$. The peak; (b) Simulated Gain plot for $3.5 \mathrm{GHz}$ indicating a Gain reported is $6.236 \mathrm{~dB}$. peak Gain of $7.17 \mathrm{dBi}$.

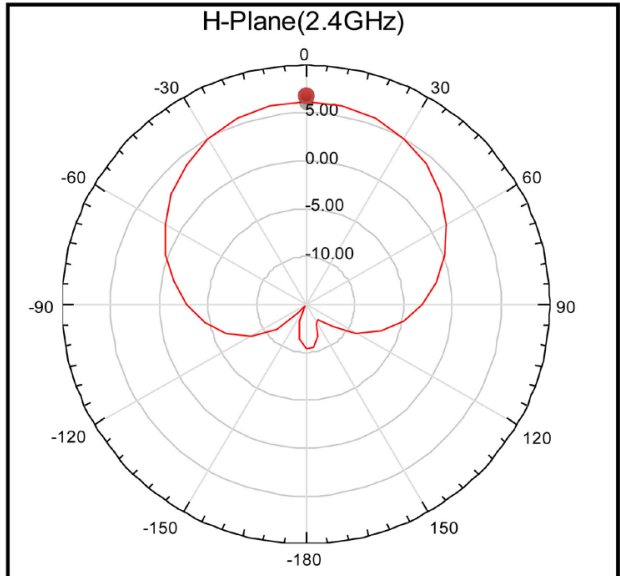

(a)

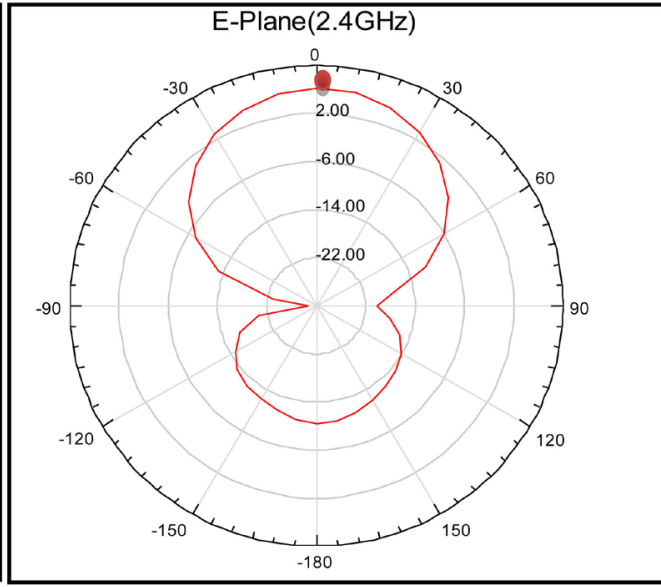

(b)

Keynote 11: The vertical Axis represents a peak gain of $6.23 \mathrm{dBi}$ for the $\mathrm{E}$ and $\mathrm{H}$ plane. The pattern is Hemispherical in $\mathrm{H}$ plane and figure of 8 in E plane.

Figure 11. Simulated radiation pattern of Antenna at $2.4 \mathrm{GHz}$ (a) under $\mathrm{H}$ plane and (b) under $\mathrm{E}$ plane. 
compared to $3.5 \mathrm{GHz}$ band indicating a good impedance match close to 50 Ohms in the lower band compared to the higher band. Both the Gain and the Bandwidths are increased by a factor of $0.9 \mathrm{~dB}$ and $88.5 \mathrm{MHz}$ in the upper compared to lower band respectively. Comparing Figure 11, we see that the peak boresignt gain is $6.23 \mathrm{dBi}$ under both $\mathrm{E}$ and the $\mathrm{H}$ plane at $2.4 \mathrm{GHz}$. But the pattern in $\mathrm{H}$ plane is Figure 8. Comparing Figure 12, we see that the peak boresight Gain is $6.5 \mathrm{~dB}$ and $7.17 \mathrm{~dB}$ under $\mathrm{H}$ and E planes. Referring to Table 3, we see that the measured Bandwidth reported is very high close to $2.16 \mathrm{GHz}$ in the upper band compared to lower band and also there is a shift in the resonant Frequency from $2.4 \mathrm{GHz}$ to $2.7 \mathrm{GHz}$ in the lower band. Referring to Table 4 and Table 5, we see that both the Gain and Bandwidths reported in the present work are high compared to other designs reported in [6] [7] and [10] at $2.4 \mathrm{GHz}$ and 3.5 GHz Frequency. Figure 15 indicates that there is a good improvement in the

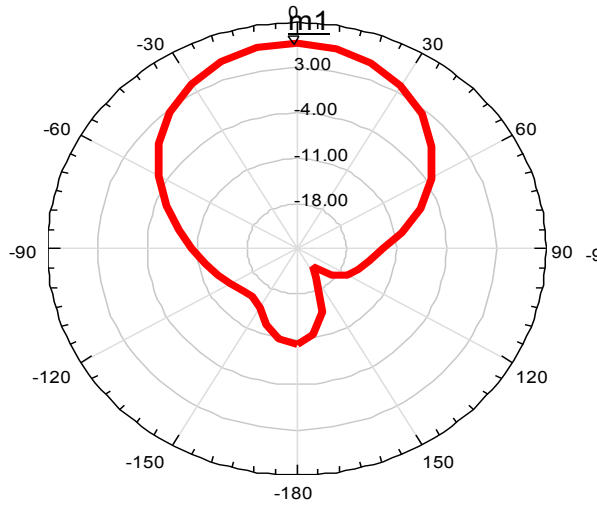

(a)

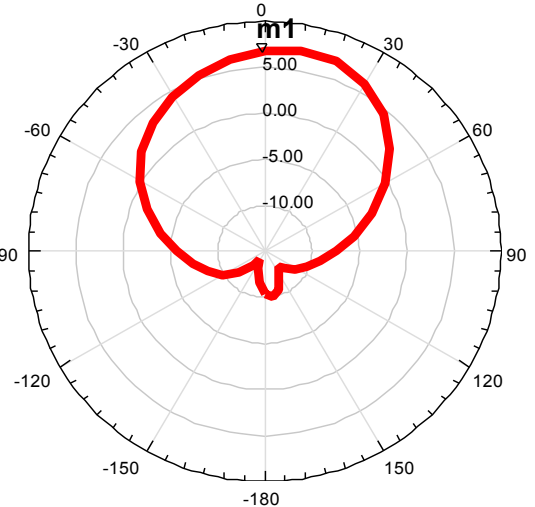

(b)

Keynote 12: the radiation pattern indicates a peak bore sight gain of $6.5 \mathrm{~dB}$ under $\mathrm{H}$ plane and 7.17 $\mathrm{dB}$ under $\mathrm{E}$ plane for $3.5 \mathrm{GHz}$.

Figure 12. Simulated radiation pattern of Antenna at $3.5 \mathrm{GHz}$ (a) $\mathrm{H}$ plane (b) E plane. From the pattern it is clear that there are some side lobes are appearing at -180 degrees.

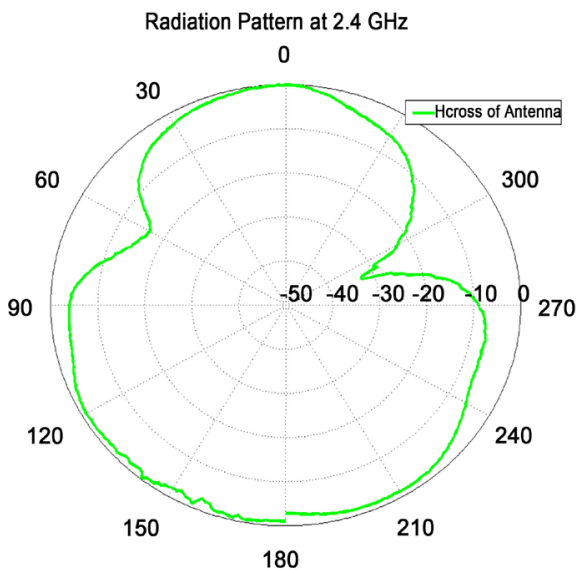

(a)

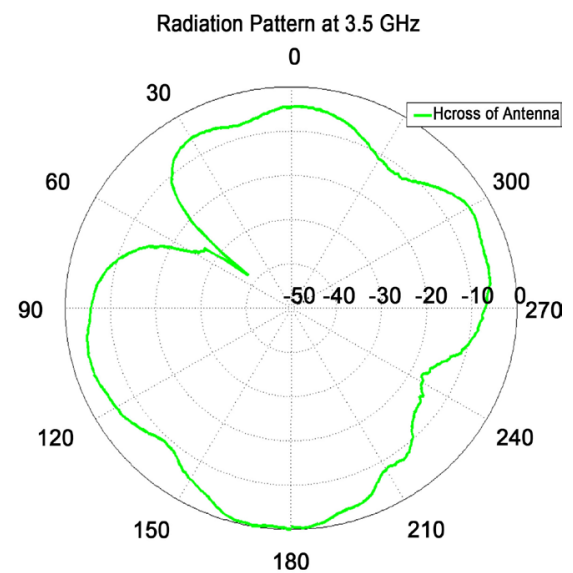

(b)

Keynote 13: The measured radiation pattern is nearly omni directional in E plane for both the frequencies.

Figure 13. Measured Normalized E-plane radiation pattern of Antenna at (a) $2.4 \mathrm{GHz}$ and (b) $3.5 \mathrm{GHz}$. 


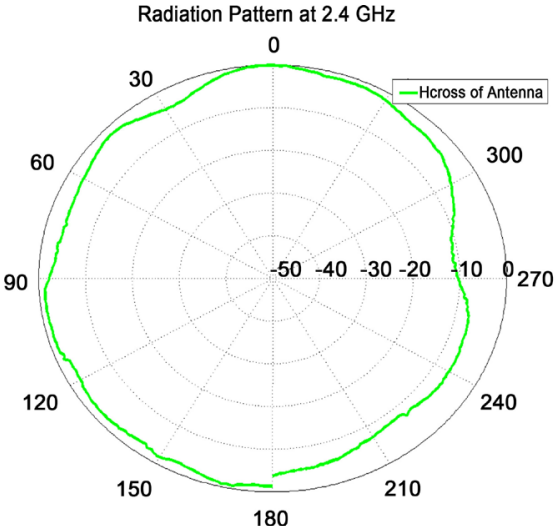

(a)

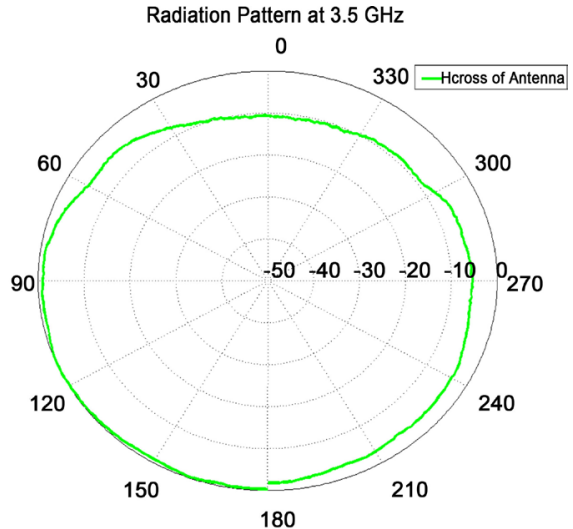

(b)

Keynote 14: The radiation pattern is nearly omni-directional for both the frequencies. The pattern is normalized to $0 \mathrm{~dB}$.

Figure 14. Measured normalized H-plane radiation pattern of Antenna at (a) $2.4 \mathrm{GHz}$ and (b) $3.5 \mathrm{GHz}$.

Table 2. Showing the comparison of the Simulated Antenna parameters at $2.4 \mathrm{GHz}$ and $3.5 \mathrm{GHz}$.

\begin{tabular}{ccc}
\hline & $2.4 \mathrm{GHz}$ & $3.5 \mathrm{GHz}$ \\
\hline Return Loss & $-31.79 \mathrm{~dB}$ & $-24.72 \mathrm{~dB}$ \\
VSWR & 1.058 & 1.123 \\
Port Impedance & $52.3825 \mathrm{Ohms}$ & $44.6874 \mathrm{Ohms}$ \\
Bandwidth & $330.2 \mathrm{MHz}$ & $412.7 \mathrm{MHz}$ \\
Gain & $6.2364 \mathrm{dBi}$ & $7.1758 \mathrm{dBi}$ \\
\hline
\end{tabular}

Table 3. Showing the comparison of the Simulated and Fabricated Antenna Results.

\begin{tabular}{ccc}
\hline & \multicolumn{2}{c}{ Simulated Results Measured Results } \\
\hline Resonant Frequency & $2.4 \mathrm{GHz}$ and $3.5 \mathrm{GHz}$ & $2.72 \mathrm{GHz}$ and $3.426 \mathrm{GHz}$ \\
VSWR & $1.058(2.4 \mathrm{GHz})$ & $1.53(2.72 \mathrm{GHz})$ \\
& $\& 1.123(3.5 \mathrm{GHz})$ & $\& 1.09(3.426 \mathrm{GHz})$ \\
Return Loss & $-31.79 \mathrm{~dB}(2.4 \mathrm{GHz})$ & $-13.38 \mathrm{~dB}(2.72 \mathrm{GHz}$ \\
& $\&-24.72 \mathrm{~dB}(3.5 \mathrm{GHz})$ & $\&-27.53 \mathrm{~dB}(3.5 \mathrm{GHz})$ \\
Bandwidth & $330.2 \mathrm{MHz}(2.4 \mathrm{GHz})$ & $0.26 \mathrm{GHz}(2.4 \mathrm{GHz})$ \\
& $\& 412.7 \mathrm{MHz}(3.5 \mathrm{GHz})$ & $\& 2.16 \mathrm{GHz}(3.5 \mathrm{GHz})$ \\
\hline
\end{tabular}

Table 4. Showing the comparison of the Simulated results reported in the paper with [6] [7] and [10] at $2.4 \mathrm{GHz}$.

\begin{tabular}{ccccc}
\hline Antenna parameters & Present work & {$[6]$} & {$[7]$} & {$[10]$} \\
\hline Return Loss & $-31.79 \mathrm{~dB}$ & $-18.0 \mathrm{~dB}$ & $-32 \mathrm{dBi}$ & $-25 \mathrm{~dB}$ \\
Bandwidth & $330.2 \mathrm{MHz}$ & $110.0 \mathrm{MHz}$ & $180 \mathrm{MHz}$ & $110 \mathrm{MHz}$ \\
Gain & $6.326 \mathrm{dBi}$ & $1.55 \mathrm{dBi}$ & $2.78 \mathrm{dBi}$ & $2.1 \mathrm{dBi}$ \\
\hline
\end{tabular}


Table 5. Showing the comparison of the Simulated results reported in the paper with [6] [7] and [10] at $3.5 \mathrm{GHz}$ frequency.

\begin{tabular}{ccccc}
\hline Antenna parameters & Present work & {$[6]$} & {$[7]$} & {$[10]$} \\
\hline Return Loss & $-24.72 \mathrm{~dB}$ & $-17.5 \mathrm{~dB}$ & $-29 \mathrm{~dB}$ & $-17.5 \mathrm{~dB}$ \\
Bandwidth & $412.7 \mathrm{MHz}$ & $700.0 \mathrm{MHz}$ & $380 \mathrm{MHz}$ & $260 \mathrm{MHz}$ \\
Gain & $7.1758 \mathrm{dBi}$ & $1.6 \mathrm{dBi}$ & $2.14 \mathrm{dBi}$ & $3.4 \mathrm{dBi}$ \\
\hline
\end{tabular}

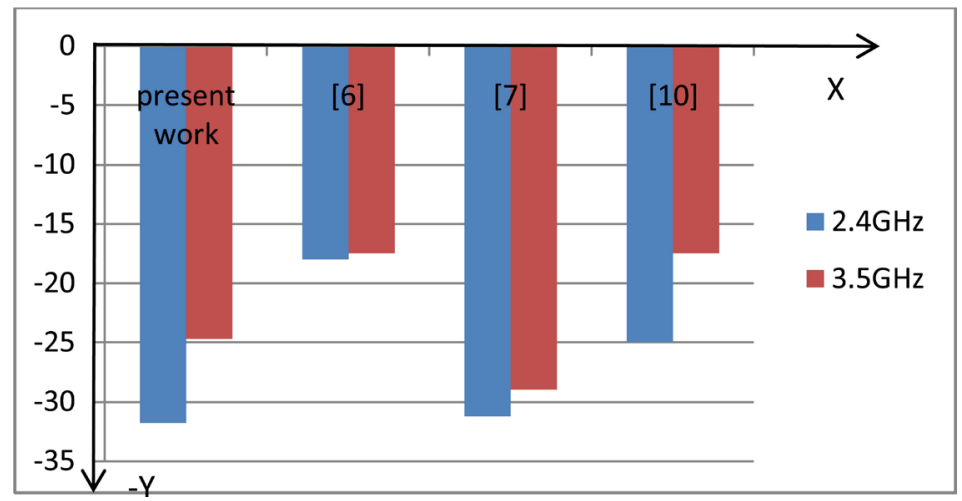

Keynote 15: X Axis represents the Reference papers and Y Axis represents the Return Loss in $\mathrm{dB}$.

Figure 15. Showing the comparison of the Simulated results reported in the paper with [6] [7] and [10] at $3.5 \mathrm{GHz}$ frequency.

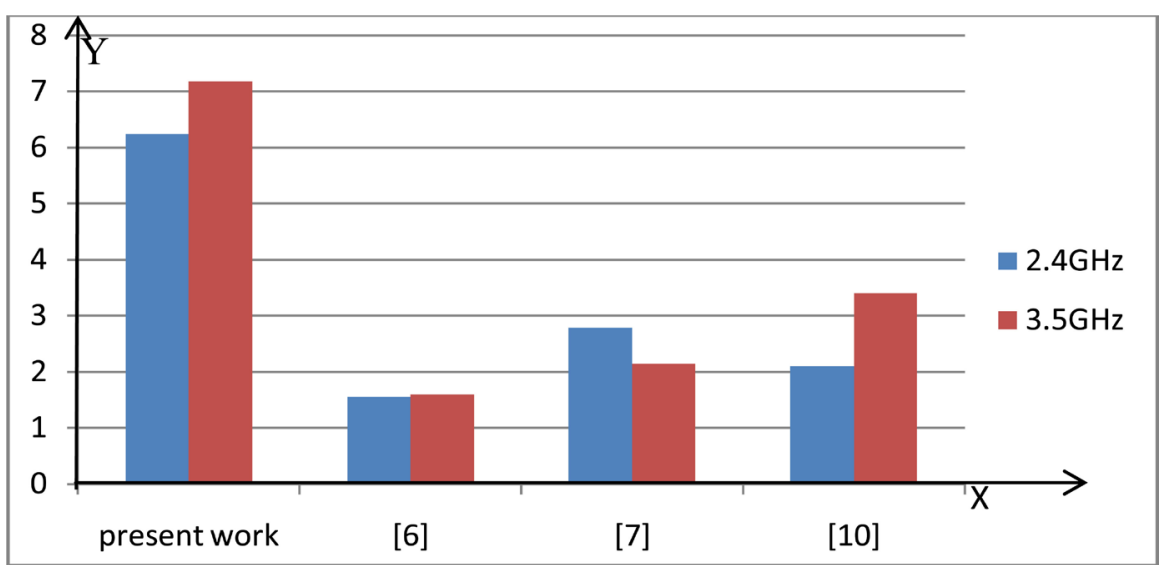

Keynote 16: X Axis represents the Reference papers and Y Axis represents the Gain in dBi.

Figure 16. Showing the comparison of the Gain reported in the present work with similar other works reported in [6] [7] and [10]. X Axis represents the Dual Frequency bands obtained in References [6] [7] \& [10] and Y Axis represents the Gain in dBi.

Return loss, namely $13.79 \mathrm{~dB}$ and $6.79 \mathrm{~dB}$ compared to [6] and [10] for the Wi-Fi Frequency band of interest. But in the Wi-Max band, there is a 7.22 $\mathrm{dB}$ improvement in the return loss compared to [6] and [10]. From Figure 16, it is clear that there is a $3.546 \mathrm{~dB}$ and $4.226 \mathrm{~dB}$ improvement in the Gain compared to [7] and [10] in the lower frequency bands of interest. While in the upper band there is a $5.03 \mathrm{~dB}$ and $3.7758 \mathrm{~dB}$ improvement in the Gain compared to [7] and [10]. As far as the Bandwidth of the Antenna is concerned Figure 17 shows that 


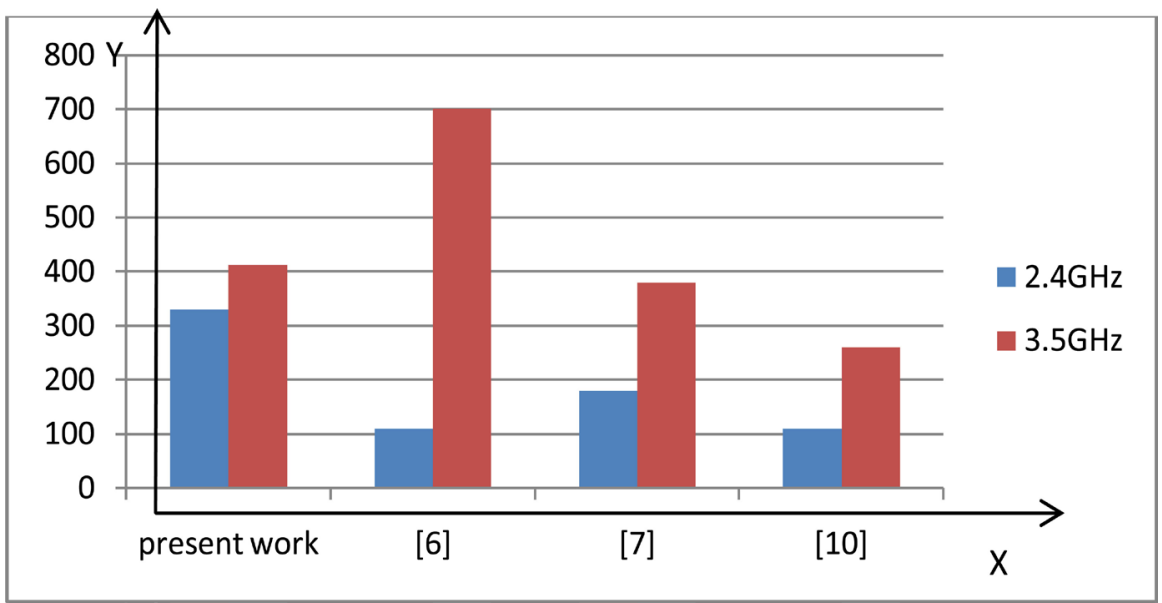

Keynote 17: $\mathrm{Y}$ Axis represents the Bandwidth in $\mathrm{MHz}$ and $\mathrm{X}$ Axis represents the Reference papers.

Figure 17. Showing the comparison of the Bandwidth reported in the present work with similar other works reported in [6] [7] and [10]. X Axis represents the Dual Frequency bands obtained in References [6] [7] \& [10] and Y Axis represents the Bandwidth in MHz.

there is a $200.2 \mathrm{MHz}$ improvement in the Bandwidth reported in the present work compared to [6] \& [10] at $2.4 \mathrm{GHz}$ frequency band. But at $3.5 \mathrm{GHz}$ frequency band, there is a $32.7 \mathrm{MHz}$ and $152.7 \mathrm{MHz}$ improvement in the Bandwidth at the upper frequency band of interest compared to [7] and [10].

\section{Conclusion}

A novel Antenna for Wi-Fi and Wi-Max band of frequencies has been proposed. It is etched on a FR4 substrate with a permittivity of 4.4. By employing two perpendicular strips, the Antenna has been made to resonate at the Dual band. The measured S11 were $-13.38 \mathrm{~dB}$ and $-27.53 \mathrm{~dB}$ for the $2.4 \mathrm{GHz}$ band and the 3.5 $\mathrm{GHz}$ band respectively. The measured bandwidth of the proposed Antenna was $0.26 \mathrm{GHz}$ and $2.16 \mathrm{GHz}$ in the lower and upper band respectively. The size of the Antenna reported is $50 \mathrm{~mm}$ by $25 \mathrm{~mm}$, thus making it compact in size.

\section{Acknowledgements}

The authors would like to thank M/s Aniritsu Technologies Limited Bangalore for helping us in characterization of the Antenna parameters for Reflection coefficient, VSWR and Bandwidth measurements using the Vector Network Analyzer model No. VNA MASTER MS2308C. The Authors would also like to thank Dr. K.J. Vinoy, Professor, IISc for allowing us to take the pattern measurement in Anachoic chamber.

\section{References}

[1] Prasanna Paga, Nagaraj, H.C., Rukmini, T.S. and Nithin, N.E. (2015) Design and Fabrication of Microstrip printed T monopole antenna for ISM applications. International Conference on Microwave, Optical and Communication Engineering, 18-20 December 2015, IIT, Bhubaneswar. https://doi.org/10.1109/ICMOCE.2015.7489742 
[2] Jithu, P., Paul, A., Pithadia, V., Misquitta, R. and Khot, U.P. (2013) Dual Band Monopole Antenna Design. International Journal of Engineering and Technology (IJET), 5, 2297-2302. http://www.enggjournals.com/ijet/docs/IJET13-05-03-036.pdf

[3] Shah, I.A., Hayat, S., Khan, I., Alam, I., Ullah, S. and Afridi, A. (2016) A Compact, Tri-Band and 9-Shape Reconfigurable Antenna for WiFi, WiMAX and WLAN Applications. International Journal of Wireless and Microwave Technologies, 5, 45-53. https://doi.org/10.5815/ijwmt.2016.05.05

[4] Huang, S.S., Li, J. and Zhao, J.Z. (2014) Design of a Compact Triple-Band Monopole Planar Antenna for WLAN/WiMAX Applications. Progress in Electromagnetics Research C, 48, 29-35. https://doi.org/10.2528/PIERC13122202

[5] Li, L., Rao, S.-H., Tang, B. and Li, M.-F. (2013) A Novel Compact Dual-band Monopole Antenna Using Defected Ground Structure. International Workshop on Microwave and Millimeter Wave Circuits and System Technology, 24-25 October 2013, Chengdu. https://doi.org/10.1109/MMWCST.2013.6814645

[6] Wang, H.J. and Li, H. A Compact Triple-Band Monopole Antenna for WLAN/WiMAX.

[7] Wang, T., Yin, Y.Z., Yang, J., Zhang, Y.L. and Xie, J.J. (2012) Compact Triple-Band Antenna Using Defected Ground Structure for WLAN/WIMAX Applications. Progress in Electromagnetics Research Letters, 35, 155-164. https://doi.org/10.2528/PIERL12082814

[8] Zahraoui, I., Errkik, A., Zbitou, J., Abdelmounim, E. and Mediavilla, A.S. (2016) A New Design of a Microstrip Antenna with Modified Ground for DCS and WiMAX Applications. International Journal of Microwave and Optical Technology, 11, No. 4.

[9] Zakaria, Z., Zainuddin, N.A., Abd Aziz, M.Z.A., Husain, M.N. and Mutalib, M.A. (2013) Dual-Band Monopole Antenna for Energy Harvesting System. IEEE Symposium on Wireless Technology and Applications (ISWTA), Kuching, Malaysia, 22-25 September 2013. https://doi.org/10.1109/iswta.2013.6688775

[10] Zhang, S.M., Zhang, F.S., Li, W.M., Li, W.Z. and Wu, H.Y. (2012) A Multi-Band Monopole Antenna with Two Different Slots for WLAN and WIMAX Applications. Progress in Electromagnetics Research Letters, 28, 173-181. https://doi.org/10.2528/PIERL11111505

[11] Huang, H., Liu, Y., Zhang, S. and Gong, S. (2015) Multiband Metamaterial-Loaded Monopole Antenna for WLAN/WiMAX Applications. IEEE Antennas and Wireless Propagation Letters, 14, 662-665.

http://or.nsfc.gov.cn/bitstream/00001903-5/320065/1/1000013482596.pdf https://doi.org/10.1109/LAWP.2014.2376969

[12] Sun, X.L., Cheung, S.W. and Yuk, T.I. (2013) Compact Dual-Band Monopole Antenna for 2.4/3.5 GHz WiMAX Applications. Progress in Electromagnetics Research Symposium Proceedings, Taipei, 25-28 March 2013. https://doi.org/10.1002/mop.27710

[13] Tan, M.-T. and Wang, B.-Z. (2016) A Dual-Band Circularly Polarized Planar Monopole Antenna for WLAN/Wi-Fi Applications. IEEE Antennas and Wireless Propagation Letters, 15, 670-673.

http://ieeexplore.ieee.org/stamp/stamp.jsp?arnumber $=7185377$ https://doi.org/10.1109/LAWP.2015.2466596

[14] Liu, W.-C., Wu, C.-M. and Dai, Y. (2011) Design of Triple-Frequency Microstrip-Fed Monopole Antenna using Defected Ground Structure. IEEE Transactions on Antennas and Propagation, 59, 2457-2463. 
https://doi.org/10.1109/TAP.2011.2152315

[15] Wu, M.-T. and Chuang, M.-L. (2015) Multibroadband Slotted Bow-Tie Monopole Antenna. IEEE Antennas and Wireless Propagation Letters, 14, 887-890.

http://ieeexplore.ieee.org/stamp/stamp.jsp?arnumber=6990588 https://doi.org/10.1109/LAWP.2014.2383441

[16] Balanis, C.A. (2008) Modern Antenna Handbook. Wiley, New York. https://doi.org/10.1002/9780470294154

Submit or recommend next manuscript to SCIRP and we will provide best service for you:

Accepting pre-submission inquiries through Email, Facebook, LinkedIn, Twitter, etc. A wide selection of journals (inclusive of 9 subjects, more than 200 journals)

Providing 24-hour high-quality service

User-friendly online submission system

Fair and swift peer-review system

Efficient typesetting and proofreading procedure

Display of the result of downloads and visits, as well as the number of cited articles Maximum dissemination of your research work

Submit your manuscript at: http://papersubmission.scirp.org/

Or contact ojapr@scirp.org 